\title{
Role of PET/CT in Diagnosis and Follow-up of Non-Hodgkin Lymphoma and Assessment of Extranodal Lymphoma
}

\author{
MAGGIE S. ABD ELGAWAD, M.Sc.; ABEER M. ABD ELHAMEED, M.D. and SAMAR R. RAGHEB, M.D. \\ The Department of Radiodiagnosis, Faculty of Medicine, Ain Shams University
}

\begin{abstract}
Background: Malignant lymphoma is the most common hematological malignancy accounts for approximately $8 \%$ of all adult malignancies. Lymphomas are broadly divided into Hodgkin lymphoma and non-Hodgkin's lymphoma. NonHodgkin lymphoma accounts for about $5 \%$ of all cases of cancer. Non-Hodgkin lymphomas have the vast majority of cases and have a greater predilection to disseminate to extranodal sites.
\end{abstract}

Aim of Study: The aim of this work is to study the role of PET/CT in the diagnosis and follow-up of Non-hodgkin lymphoma and assess its extranodal extention.

Patients and Methods: The study was conducted on thirty patients where the diagnosis of non-hodgkin lymphoma have been pathologically confirmed, 18 males $(60 \%)$ and 12 females (40\%), their ages are ranged between 19 to 73 years old. All patients were subjected to full history taking, laboratory testing, biopsy and histopathology, the studied cases according to pathalogical type of non-Hodgkin lymphoma mostly were of B-cell type (80\%) and (20\%) T-cell type, CT scan and $\mathrm{PET} / \mathrm{CT}$ examination. All patients were examined using Siemens Bio-graph true point PET/CT scanner.

Results: Extranodal involvement was detected by PET/CT in 16 patients $(53.3 \%)$. Their distribution was as follows; head and neck: 4 patients (13.3\%), lung: 3 patients (10\%), abdomen: 12 patients (40\%), MSK: 10 patients (33.3\%), while CECT detected 8 patients had extra nodal involvement their distribution was as follow; head and neck: 2 patients $(6.6 \%)$, lung: 1 patient (3.3\%), abdomen:7 patients (43.7\%), MSK: 6 patients $(16.6 \%)$.

Thirty patients referred for initial assessment SUV max among the 30 patients referred for initial assessment ranged from 3.7-34.0 with mean value of $16.91 \pm 8.07 \mathrm{SD}$.

In aggressive type of NHL SUVmax ranged from 10.534.0 with mean value of $19.9 \pm 6.65 \mathrm{SD}$, the aggressive type of NHL is significantly higher $(p \leq 0.01)$ than in indolent type.

The cases were staged according to the size in CECT and FDG activity in PET/CT; CECT detected 6 patients $(20 \%)$ in

Correspondence to: Dr. Maggie S. Abd Elgawad, The Department of Radiodiagnosis, Faculty of Medicine, Ain Shams University stage I, 9 patients $(29.3 \%)$ in stage II, 7 patients $(23.3 \%)$ in stage III and 8 patients $(26.7 \%)$ in stage IV. The PET/CT detected 4 patients (13.3\%) in stage I, 8 patients $(26.7 \%)$ in stage II, 5 patients $(16.7 \%)$ in stage III and $13(43.3 \%)$ patients in stage IV, therefore PET/CT was statistically significant at $p \leq 0.0004$ in the initial staging.

In follow-up assessment among the 20 patients referred after treatment; SUVmax among the 20 patients referred for follow-up assessment, their SUVmax of the initial PET/CT examination ranged from 3.7-34.0 with a mean value of 17.57 \pm $8.54 \mathrm{SD}$, with a significant change $(p \leq 0.046)$ in their followup examination with SUVmax ranged from 0.0-28.0 with a mean value of $11.73 \pm 9.25 \mathrm{SD}$

CECT showed 4 patients (20\%) in complete regression, 13 patients $(65 \%)$ in stable disease and 1 patient $(5 \%)$ in progressive disease while PET/CT showed 7 patients $(35 \%)$ in complete remission, 4 patients $(20 \%)$ in partial remission, $0(0.0 \%)$ patients in stationary disease, $9(45 \%)$ patients in progressive disease. Thus, PET/CT was concordant with CECT in $6(30 \%)$ cases and disagreed with CECT in $14(70 \%)$ cases with significance $(p \leq 0.015)$.

Conclusion: PET/CT agreed with CECT in the initial staging of $13(43.3 \%)$ cases while disagreed with CECT in initial staging of $17(56.7 \%)$ cases, where PET/CT upstaged $13(43.3 \%)$ cases and down staged $4(13.3 \%)$ cases.

In follow-up PET/CT was concordant with CECT in 9 $(45 \%)$ cases and disagreed with CECT in $14(55 \%)$ cases with significance $(p \leq 0.034)$.

Key Words: PET/CT - Non-Hodgkin Lymphoma - Extranodal Lymphoma.

\section{Introduction}

LYMPHOMA is a blood cancer that occurs to B or T lymphocytes, the white blood cells that form a part of the immune system and help protect the body [1]. The hallmark of the disease is the enlargement and proliferation of lymph nodes or secondary lymphoid tissues. The choice of treatment strategy and prognosis of lymphoma essentially depends 
on grade, histological subtype and stage of the disease [1] .

Malignant lymphoma is the most common haematological malignancy, it accounts for approximately $8 \%$ of all adult malignancies and considered one of the most curable forms of cancer [2]

The lymph proliferative disorders are broadly divided into Hodgkin's and non-Hodgkin's lymphoma [3]. Several classifications exist for lymphoma, including the Ann Arbor classification with Cotswolds modifications and the Revised EuropeanAmerican Lymphoma (REAL) classification [4].

The term extra nodal disease refers to lymphomatous infiltration of anatomic sites other than the lymph nodes. The prevalence of extra nodal involvement in non-Hodgkin lymphoma and Hodgkin disease has increased in the past decade [2]

Extra nodal lymphoma occurs in about $40 \%$ of patients with lymphoma. It is observed more frequently in NHL than with HL, and is often intermediate to high grade [5].

18-Ffluorodeoxyglucose (18F-FDG) is a glucose analogue that provides unique information about glucose metabolism of normal and abnormal tissues; it is preferentially taken up and accumulated in the malignant cells relative to non-malignant cells [6]. However, PET is limited by the lack of morphological information and low anatomical resolution [7]. Thus fusion of images of PET and CT obtained at the same position provides the precise anatomical and functional information about the lesions with increased glucose metabolism over the whole body in a single session [8] .

PET/CT scanning allows the investigator to visualize and measure the intensity of residual metabolic activity within a lesion as well as estimating its size [9], and PET/CT is a more accurate initial staging examination than conventional diagnostic CT, particularly for the detection of unexpected sites of extra nodal lymphoma [10]

\section{Aim of the work:}

Assess the value of PET/CT in the diagnosis and follow-up of non Hodgkin lymphoma as well as the assessment of its extra nodal extension. To assess the response after treatment with chemotherapy.

\section{Patients and Methods}

This prospective study was conducted on 30 patients 18 males (60\%) and 12 females (40\%), their ages are ranged between 19 to 73 years old, with a mean age of $46.60 \pm 16.45$ years. Referred from different oncology centers, where the diagnosis of non-Hodgkin lymphoma have been pathologically confirmed (FNAC or excision biopsy). Referred to the (Nuclear Medicine Department in the Radio Diagnosis Department) of (Sharq ElMadina Hospital in Alexandria). For initial assessment in thirty patients, included twenty patients of them for follow-up after received chemotherapy. The PET/CT combined with CT was used in the assessment in period from (3/2019 till/12/2019), to compare between stages of the disease and response of treatment as well as assess its extra nodal extension.

\section{Inclusion criteria:}

1- Any age group and sex.

2- Patients with diagnosis of non-Hodgkin lymphoma who have been confirmed by biopsy and/or still under treatment, referred to PET/CT for assessment.

3- Patients with extra nodal lymphoma.

Exclusion criteria:

- Patients still undiagnosed.

- Patients diagnosed with Hodgkin lymphoma.

- Uncontrolled diabetes mellitus.

Methods:

Patients were subjected to the following:

1- Full history taking.

2- Laboratory testing.

3- Biopsy and histopathology (either FNAC or excisional biopsy).

4- CECT scan.

\section{5- PET/CT examination:}

Exams were done and data were obtained using Siemens Bio-graph true point PET/CT scanner. These dedicated systems integrate a PET scanner with a multi-slice helical CT scanners permit the acquisition of co-registered CT and PET images in one session.

\section{Imaging protocol:}

\section{Patient preparation:}

All patients were asked to fast for six hours prior to scan. All metallic items were removed from the patients and they were given gown to wear. Patients were asked to empty their bladders before the procedure. An I.V. cannula was inserted in the patient's arm for administration of 18F-FDG. 
The patients were instructed to avoid any kind of strenuous activity prior to the examination and following injection of the radioisotope to avoid physiologic muscle uptake of FDG and the patient was asked to void prior to scanning. Serum glucose was routinely measured prior to $18 \mathrm{~F}-\mathrm{FDG}$ injection, and fasting levels were $70-170 \mathrm{mg} / \mathrm{dl}$. In breast feeding women, it was recommended that breast feeding discontinue for approximately 24 hours after the 18F-FDG injection because of 18F-FDG accumulation in breast milk. The strategies for decreasing brown fat were; providing a controlledtemperature (warm) environment for patients before 18F-FDG injection and high-fat, low-carbohydrate, protein-permitted diet before the examination.

\section{Dosage administration of FDG:}

About one liter of negative oral contrast agent (5\% mannitol) approximately one hour before the exam. A dose of $0.1 \mathrm{mCi} / \mathrm{kg}$ of $18 \mathrm{~F}-\mathrm{FDG}$ IV injection 45-90 minutes before examination was administered.

\section{Patient position:}

The patients were positioned in a comfortable head fixation with arms up.

\section{Scanning Technique:}

I- CT Technique: Helical CT was performed following injection of about $125 \mathrm{~mL}$ of a noniodinated contrast medium at a rate of $4 \mathrm{~mL} / \mathrm{sec}$ using a power injector. For a typical whole body PET/CT study (neck, chest, abdomen, and pelvis), scanning began at the level of the skull base and extended caudally to the level of the upper thighs. The total length of CT coverage was an integral number of bed positions scanned during acquisition of PET data. The study was performed with the patient breathing quietly. Scanning parameters are collimation width of $5.0 \mathrm{~mm}$, pitch of 1.5 , and gantry rotation time of 0.8 second and field of view of $50 \mathrm{~cm}$. The helical data are retrospectively reconstructed at one $\mathrm{mm}$ intervals.

II- PET Technique: PET was performed following the CT study without moving the patient. Approximately six to seven bed positions are planned in the three-dimensional acquisition mode for scanning the entire patient with 3-5 minute acquisition at each bed position.

III- PET/CT fusion: Hundreds of trans-axial PET and CT images were first reconstructed. These are then reformatted into coronal and sagittal images to facilitate image interpretation. For each of these sets of PET and CT images, corresponding fusion images, combining the two types of data, also were generated. The whole acquisition time for an integrated PET/CT scan was approximately 25-30mins. PET image data sets were reconstructed using CT data for attenuation correction and coregistered images were displayed using special software.

\section{PET/CT interpretation:}

All PET/CT examinations were analyzed by a consensus of two experienced radiologists. The PET images and the volume of CT scans were evaluated for the presence and extent of 18F-FDGpositive lymphoma in different lymph nodes groups and the presence of extra-nodal disease involvement in the initial studies as well as for residual/recurrent abnormalities after therapy.

Abnormal 18F-FDG uptake was defined as radiotracer accumulation outside the normal anatomic structures and of greater intensity than background activity, excluding normal areas of physiological uptake. In all cases estimation of 18-FDG uptake was done using SUVmax values for each group of enlarged nodes or mass lesion.

\section{Statistical analysis:}

Data were fed to the computer and analyzed using IBM SPSS software package version 20.0. (Armonk, NY: IBM Corp). Qualitative data were described using number and percent. The Kolmogorov-Smirnov test was used to verify the normality of distribution.

Quantitative data were described using range (minimum and maximum), mean, standard deviation and median. Significance of the obtained results was judged at the $5 \%$ level.

\section{Results}

Table (1) shows that the majority of the study sample $(60 \%)$ were males. Also shows that nearly half of the sample about (43.3\%) were in the age group $(>50)$ years old.

Table (2) shows the distribution of the studied cases according topathalogical type of non-Hodgkin lymphoma mostly were of B-cell type (80\%), and (20\%) T-cell type.

Table (3) shows the distribution of extra nodal lesions detected by PET/CT in comparison to detected by CECT ( $\mathrm{n}=33$ lesions) was detected by PET/CT in 16 patients (53.3\%) their distribution was as follows; head and neck: 4 patients (13.3\%), lung: 3 patients (10\%), abdomen: 12 patients $(40 \%)$, MSK: 10 patients (33.3\%), while CECT detected 
8 patients had extra nodal involvement their distribution was as follow; head and neck: 2 patients (6.6\%), lung: 1 patient (3.3\%), abdomen: 7 patients (43.7\%), MSK: 6 patients (16.6\%).

Table (4) shows that SUVmax among the 30 patients referred for initial assessment ranged from 3.7-34.0 with mean value of $16.91 \pm 8.07 \mathrm{SD}$, in aggressive type of NHL SUVmax ranged from 10.5-34.0 with mean value of 19.9 $\pm 6.65 \mathrm{SD}$ and that of indolent NHL ranged from 3.7-10.0 with a mean value of $7.10 \pm 2.49$, the aggressive type of NHL is significantly higher $(p \leq 0.01)$ than in indolent type.

Table (5) shows the relation in the initial staging between (PET/CT) staging and CECT scan staging $(n=30)$ that CECT detected most of patients 9 patients $(29.3 \%)$ were in stage II. The PET/CT detected most of patients $13(43.3 \%)$ patients were in stage IV, therefore PET/CT was statistically significant at $p \leq 0.0004$.

Table (6) shows SUVmax among the 20 patients referred for follow-up assessment, their SUVmax of the initial PET/CT examination ranged from 3.7-34.0 with a mean value of $17.57 \pm 8.54 \mathrm{SD}$, with a significant change $(p \leq 0.046)$ in their follow-up examination with SUVmax ranged from 0.0-28.0 with a mean value of $11.73 \pm 9.25 \mathrm{SD}$.

Table (7) shows that among the 20 patients referred for follow-up assessment after treatment according to the size in CECT and FDG activity in PET/CT; CECT showed most of patients, 9 patients $(45 \%)$ were in stable disease, while PET/CT showed that most of patients, $9(45 \%)$ patients were in progressive disease with significance $(p \leq 0.034)$.

Fig. (1): Clarifies that assessment by PET/CT and CECT axial initial and follow-up images show partial remission of mass lesion at the left lateral wall of the oropharynx centered upon the left tonsil region and multiple bilateral cervical lymphadenopathy right cervical level II lymph node which is FDG-avid with SUVmax=12.5.

Fig. (2): Shows corresponding PET/CT and CECT axial initial and follow-up images show progression of a large ill-defined amalgamated nodal mass is seen involving anterior mediastinal/retro-sternal perivascular infiltrating anterior chest wall at para-sternal region bilaterally with high grade activity. This nodal mass globally measured $11 \times 9.2 \times 9 \mathrm{~cm}$ with SUVmax $=23$.
Table (1): Distribution of the studied cases according to demographic data $(n=30)$.

\begin{tabular}{lll}
\hline & No. & $\%$ \\
\hline Sex: & & \\
Male & 18 & 60.0 \\
Female & 12 & 40.0 \\
Age (years): & & \\
$<30$ & 6 & 20.0 \\
$30-50$ & 11 & 36.7 \\
$>50$ & 13 & 43.3 \\
Min.-Max. & \multicolumn{2}{c}{$19.0-73.0$} \\
Mean \pm SD. & $46.60 \pm 16.45$ \\
Median & \multicolumn{2}{c}{49.0} \\
\hline
\end{tabular}

Out of the 30 studied patients pathologically proven, 24 patients (80\%) were of B-cell type, 6 patients were $(20 \%)$ of T-cell type.

Table (2): Distribution of the studied cases according to pathalogical type of non-Hodgkin lymphoma. $(n=30)$.

\begin{tabular}{lll}
\hline Type of non-Hodgkin lymphoma & No. & $\%$ \\
\hline B-cell type: & 24 & 80 \\
LBCL & 16 & 53.3 \\
Folicullar lymphoma & 6 & 20.0 \\
Mantle cell lymphoma & 1 & 3.3 \\
Marginal zone & 1 & 3.3 \\
T-cell type & 6 & 20 \\
\hline
\end{tabular}

Table (3): Distribution of extra nodal lesions detected by PET/CT in comparison to detected by CECT $(n=$ 33 lesions).

\begin{tabular}{|c|c|c|c|c|c|c|}
\hline & \multicolumn{2}{|c|}{ PET/CT } & \multicolumn{2}{|c|}{ CECT } & \multirow{2}{*}{$x^{2}$} & \multirow{2}{*}{$p$} \\
\hline & No. & $\%$ & No. & $\%$ & & \\
\hline - $\mathrm{H} \& \mathrm{~N}$ & 4 & 12.1 & 2 & 6.1 & 0.733 & $\mathrm{FE}_{p}=0.672$ \\
\hline - Parotid & 2 & 6.1 & 1 & 3.0 & 0.349 & $\mathrm{FE}_{p=1.000}$ \\
\hline - Thyroid & 1 & 3.0 & 0 & 0.0 & 1.015 & $\mathrm{FE}_{p=1.000}$ \\
\hline - Tonsillar & 1 & 3.0 & 1 & 3.0 & 0.0 & $\mathrm{FE}_{p=1.000}$ \\
\hline - Chest & 3 & 9.1 & 1 & 3.0 & 1.065 & $\mathrm{FE}_{p}^{\prime}=0.613$ \\
\hline $\begin{array}{l}\text { Pulmonary } \\
\text { nodules \& } \\
\text { Atelectatic } \\
\text { band }\end{array}$ & 2 & 6.1 & 1 & 3.0 & 0.349 & $\mathrm{FE}_{p=1.000}$ \\
\hline - Pleural effusion & 1 & 3.0 & 0 & 0.0 & 1.015 & ${ }^{\mathrm{FE}} p=1.000$ \\
\hline • GIT & 14 & 42.4 & 10 & 30.3 & 1.048 & 0.306 \\
\hline - Liver & 4 & 12.1 & 3 & 9.1 & 0.160 & $\mathrm{FE} p=1.000$ \\
\hline • SPL & 8 & 24.2 & 6 & 18.2 & 0.363 & 0.547 \\
\hline - Stomach & 2 & 6.1 & 1 & 3.0 & 0.349 & $p=1.000$ \\
\hline •INT & 0 & 0.0 & 0 & 0.0 & & - \\
\hline - MSK & 12 & 36.4 & 6 & 18.2 & 2.750 & 0.097 \\
\hline • BM & 7 & 21.2 & 4 & 12.1 & 1.065 & $\mathrm{FE}_{p}=0.613$ \\
\hline • Muscle & 2 & 6.1 & 1 & 3.0 & 0.349 & ${ }^{\mathrm{FE}} p=1.000$ \\
\hline - Cortical bone & 3 & 9.1 & 1 & 3.0 & 0.982 & $\mathrm{FE}_{p}=0.322$ \\
\hline Total & 33 & $100 \%)$ & 19 & $57.6 \%$ & $9.130^{*}$ & $0.016^{*}$ \\
\hline
\end{tabular}

*Some patients presented with more than one site of extranodal involvement.

$\chi$ : Chi square test. FE: Fisher Exact.

$p: p$-value for comparing between PET/CT and CECT.

*: Statistically significant at $p \leq 0.05$.

Agreement: (57.6\%). Disagreement: (42.4\%). 


\section{According to grade of lymphoma:}

The lymphomas are generally FDG-avid. The $\mathrm{HL}$ is known to have intense FDG uptake while the NHL can be classified into different grades weather indolent or aggressive according the FDG uptake measured by the SUVmax.

Table (4): Distribution of the studied cases according to SUV baseline ( $n=30)$.

\begin{tabular}{lccllccc}
\hline SUV baseline & No. & $\%$ & Min.-Max. & Mean \pm SD & Median & Z & $p$ \\
\hline Indolent & 7 & 23.3 & $3.70-10.0$ & $7.10 \pm 2.49$ & 6.70 & 11.398 & 0.01 * \\
Aggressive & 23 & 76.7 & $10.50-34.0$ & $19.89 \pm 6.65$ & 18.0 & & \\
\hline
\end{tabular}

$\mathrm{Z}, p: \mathrm{Z}$ and $p$-values for Wilcoxon signed ranks test for comparing between indolent and aggressive type.

*: Statistically significant at $p \leq 0.05$.

Table (5): Relation between (PET/CT) staging and CECT scan staging ( $\mathrm{n}=30)$.

\begin{tabular}{|c|c|c|c|c|c|c|c|c|c|c|c|c|}
\hline \multirow{3}{*}{$\begin{array}{l}\text { CECT } \\
\text { scan } \\
\text { staging }\end{array}$} & \multicolumn{10}{|c|}{ Stage (PET/CT) } & \multirow{3}{*}{$x^{2}$} & \multirow{3}{*}{$\mathrm{MC}_{p}$} \\
\hline & \multicolumn{2}{|c|}{$\begin{array}{c}\text { Stage I } \\
(\mathrm{n}=4)\end{array}$} & \multicolumn{2}{|c|}{$\begin{array}{l}\text { Stage II } \\
(\mathrm{n}=5)\end{array}$} & \multicolumn{2}{|c|}{$\begin{array}{l}\text { Stage IIE } \\
(\mathrm{n}=3)\end{array}$} & \multicolumn{2}{|c|}{$\begin{array}{c}\text { Stage III } \\
(\mathrm{n}=5)\end{array}$} & \multicolumn{2}{|c|}{$\begin{array}{c}\text { Stage IV } \\
(\mathrm{n}=13)\end{array}$} & & \\
\hline & No. & $\%$ & No. & $\%$ & No. & $\%$ & No. & $\%$ & No. & $\%$ & & \\
\hline Stage I & 3 & 75.0 & 2 & 40.0 & 1 & 33.3 & 0 & 0.0 & 0 & 0.0 & $28.917 *$ & $0.004 *$ \\
\hline Stage II & 1 & 25.0 & 1 & 20.0 & 1 & 3.3 & 3 & 60.0 & 1 & 7.7 & & \\
\hline Stage IIE & 0 & 0.0 & 0 & 0.0 & 1 & 33.3 & 0 & 0.0 & 1 & 7.7 & & \\
\hline Stage III & 0 & 0.0 & 2 & 40.0 & 0 & 0.0 & 1 & 20.0 & 4 & 30.8 & & \\
\hline Stage IV & 0 & 0.0 & 0 & 0.0 & 0 & 0.0 & 1 & 20.0 & 7 & 53.8 & & \\
\hline
\end{tabular}

\begin{tabular}{lcccc}
\hline SUVmax & Suvmax baseline & Suvmax follow-up & $\mathrm{Z}$ & $p$ \\
\hline Min.-Max. & $3.7-34.0$ & $0.0-28.0$ & $1.998^{*}$ & $0.046^{*}$ \\
Mean \pm SD. & $17.57 \pm 8.54$ & $11.73 \pm 9.25$ & & \\
Median & 16.75 & 9.50 & & \\
\hline
\end{tabular}

\begin{tabular}{|c|c|c|c|c|c|c|c|c|c|c|}
\hline \multirow[t]{2}{*}{$\begin{array}{l}\text { Course CECT } \\
\text { follow-up }\end{array}$} & \multicolumn{2}{|c|}{$\begin{array}{l}\text { Complete } \\
\text { remission } \\
\quad(n=7)\end{array}$} & \multicolumn{2}{|c|}{$\begin{array}{l}\text { Partial } \\
\text { remission } \\
(n=4)\end{array}$} & \multicolumn{2}{|c|}{$\begin{array}{l}\text { Stable } \\
(\mathrm{n}=0)\end{array}$} & \multicolumn{2}{|c|}{$\begin{array}{l}\text { Progressive } \\
\qquad(\mathrm{n}=9)\end{array}$} & \multirow[t]{2}{*}{$\chi^{2}$} & \multirow[t]{2}{*}{$\mathrm{MC}_{p}$} \\
\hline & No. & $\%$ & No. & $\%$ & No. & $\%$ & No. & $\%$ & & \\
\hline Complete remission & 5 & 71.4 & 0 & 0.0 & 0 & 0.0 & 0 & 0.0 & $11.398 *$ & $0.034 *$ \\
\hline Partial remission & 1 & 14.3 & 1 & 25.0 & 0 & 0.0 & 0 & 0.0 & & \\
\hline Stable & 1 & 14.3 & 0 & 0.0 & 0 & 0.0 & 8 & 88.9 & & \\
\hline Progressive & 0 & 0.0 & 3 & 75.0 & 0 & 0.0 & 1 & 11.1 & & \\
\hline
\end{tabular}

A 49 years old male with pathologically proven LBCL presented by anorexia and weight loss, referred for initial assessment and follow-up after chemotherapy.
A 46 years old female with pathologically proven LBCL presented with anorexia, weight loss and recurrent chest infections referred for initial assessment and follow-up after chemotherapy. 

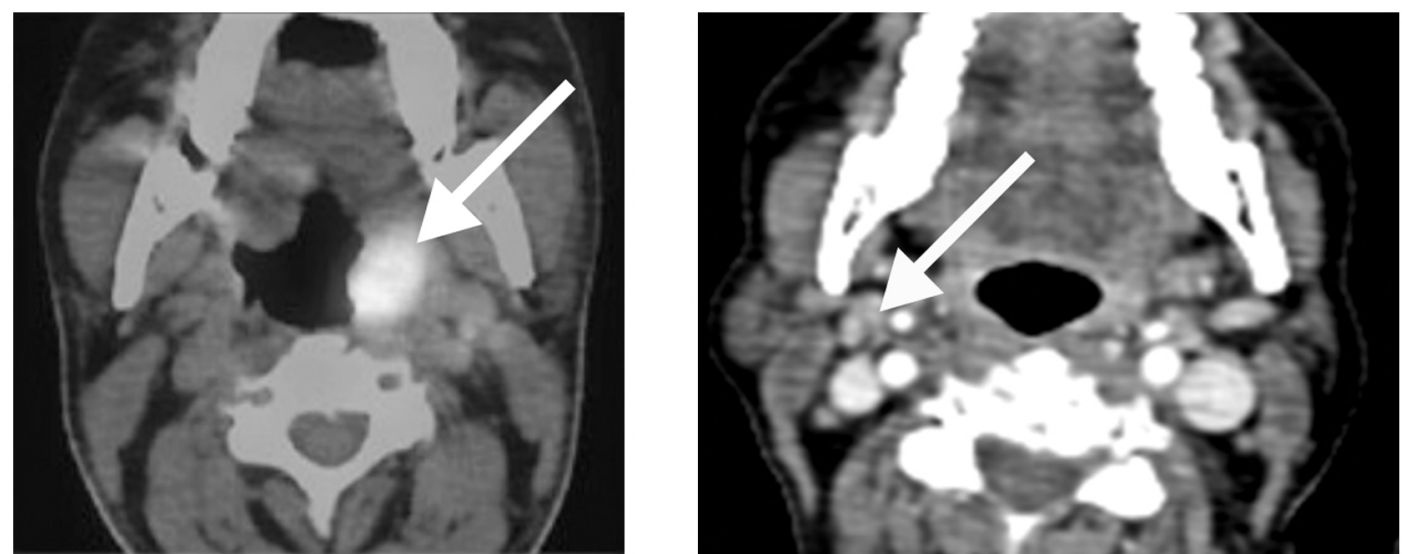

(A)
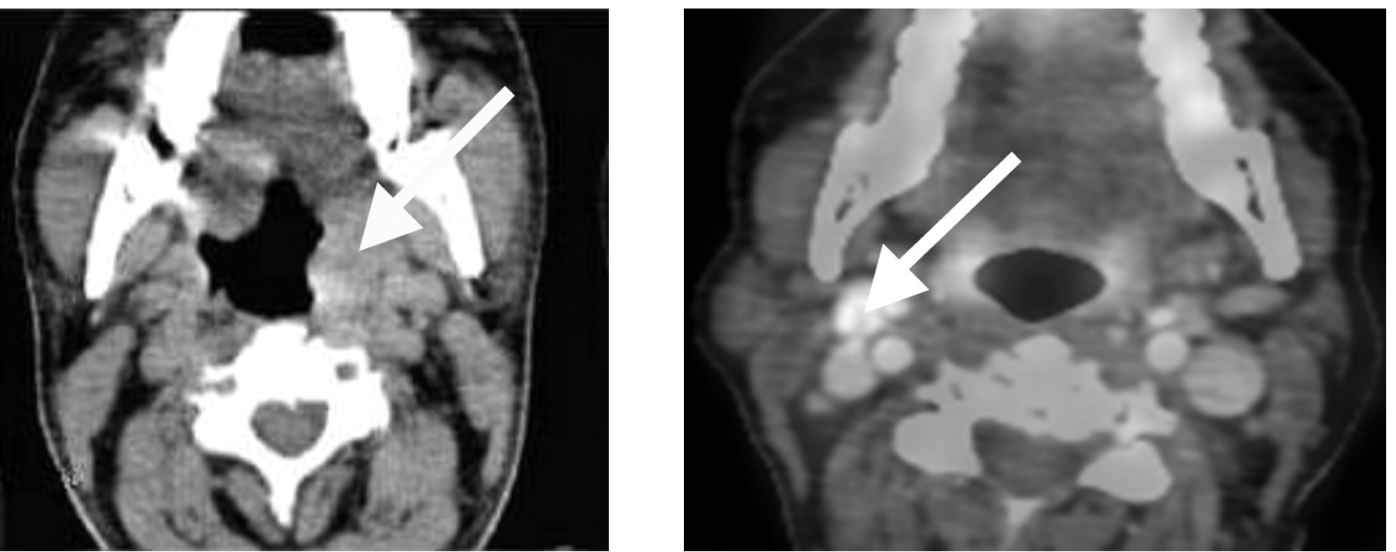

Fig. (1): The patient is referred for initial assessment by PET/CT and CECT axial images (A) Show mass lesion at the left lateral wall of the oropharynx centered upon the left tonsil region. It measures $3.5 \mathrm{X} 4 \mathrm{X} 4 \mathrm{~cm}$ in dimensions with SUVmax $=29.5$. It is seen compromising the oropharynx air column and encroaching upon the parapharyngeal space. Follow-up (B) After chemotherapy shows partial remission of previous tonsillar lesion and multiple bilateral cervical lymphadenopathy right cervical level II lymph node which is FDG-avid with SUVmax=12.5.
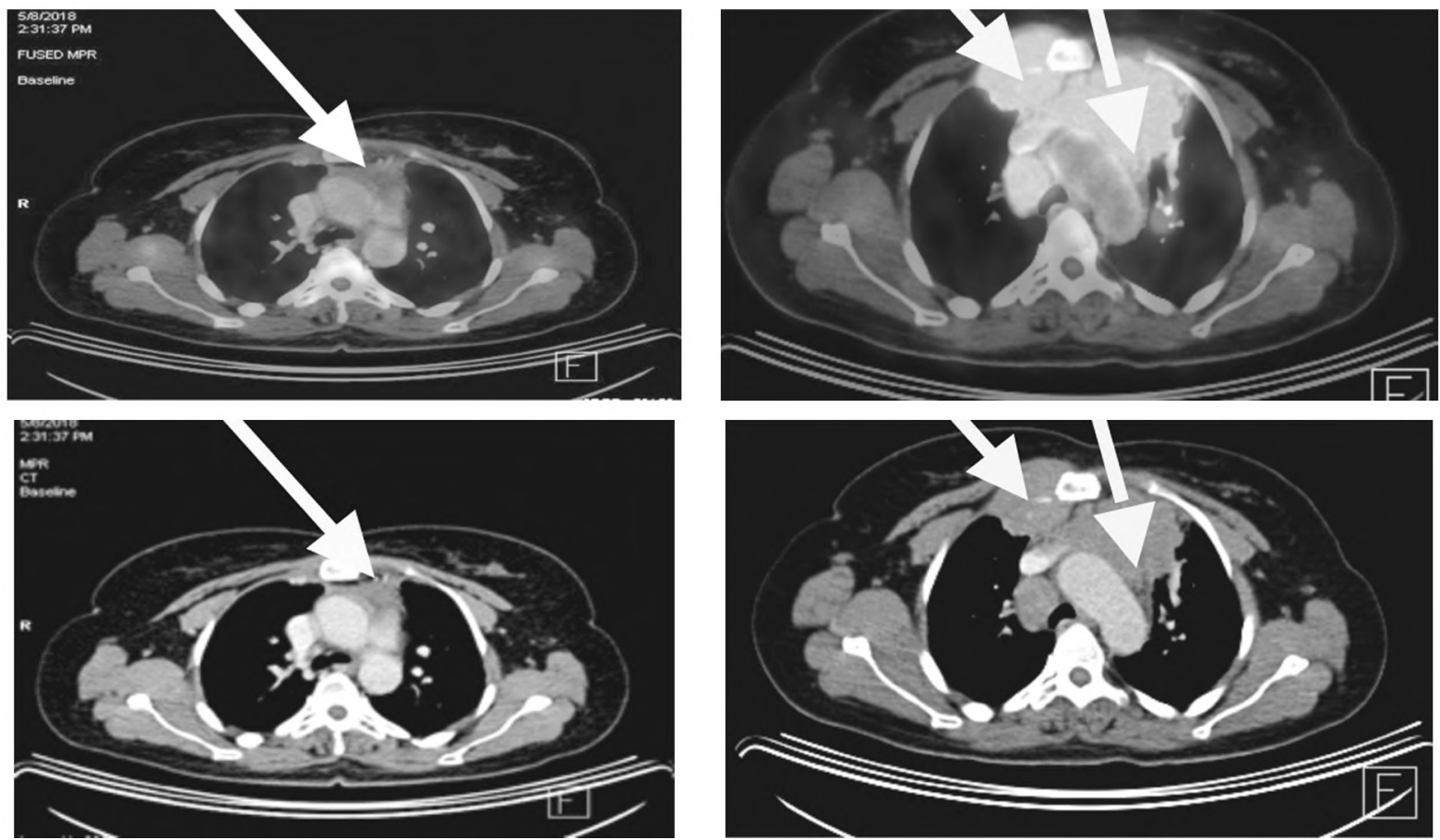

(B)

Fig. (2): (A) Initial corresponding PET/CT and CECT axial images: Show anterior. Mediastinal and peri-vascular mediastinal amalgamated noda with SUVmax=1. (B) Follow-up study after three months shows progression of a large ill-defined amalgamated nodal mass is seen involving anterior mediastinal/retro-sternal perivascular infiltrating anterior chest wall at para-sternal region bilaterally with high grade activity. This nodal mass globally measured 11 X 9.2 X $9 \mathrm{~cm}$ with SUVmax $=23$ 


\section{Discussion}

Lymphoma comprises a histologically heterogeneous group of cancers derived from the immune system cells. The hallmark of the disease is the enlargement and proliferation of lymph nodes or secondary lymphoid tissues. NHL and Hodgkin disease may also arise from or involve almost any organ of the human body. The term extra-nodal lymphoma has been used to describe this uncommon form of lymphoid malignancy, in which there is neoplastic proliferation at sites other than the expected native lymph nodes or lymphoid tissues [2].

This study was conducted on 30 patients have pathologically proven non-Hodgkin lymphoma with age ranged between 19 to 73 and mean age of $46.60 \pm 16.45$ years old.

Among the 30 patients, $18(60 \%)$ were males and $12(40 \%)$ were females with a higher incidence in the males, among which $24(80 \%)$ patients were of B-cell type and 6 patients (20\%) of T-cell type, with a higher incidence of B-cell subtype.

Extra nodal disease refers to lymphomatous infiltration of anatomic sites other than the lymph nodes [2].

In our current study, extra nodal involvement was detected in 16 patients (53.3\%) their distribution was as follows; head and neck: 4 patients (13.3\%), lung: 3 patients (10\%), abdomen: 12 patients (40\%), MSK: 10 (33.3\%) patients.

Several reports showed that PET/CT can detect more extra-nodal disease sites than PET or CT. PET/CT was significantly better in detecting extranodal lesions than CT $(p<0.016)$ and. Of the 36 extra-nodal lesions, PET/CT detected 25 extranodal lesions versus 16 by CT [12]

We obtained similar results in our study and supported this theory, as of 16 patients with extra nodal lesions, PET/CT was able to detect 33 FDGavid lesions while CECT detected only 19/33 lesions $(46.7 \%)$ with statistically significance for PETCT $p<0.16$.

Head and neck involvement is the second most common site of NHL. Primary NHL of the salivary glands is relatively uncommon and most often occurs in the parotid gland. Primary lymphoma of the thyroid gland is rare, with only about $2 \%$ of extranodal lymphomas arising within this gland [13].
In this current study $4(13.3 \%)$ patient had extranodal sites in the head and neck distributed as; 2 patients $(6.7 \%)$ had parotid gland involvement, 1 patient had tonsillar lesion (3.3\%) while 1 patient thyroid gland involvement.

Intrathoracic disease was noted in $40-50 \%$ of patients with NHL at presentation pulmonary involvement presents as solitary or multiple nodules or masses, reticulonodular opacities, and consolidation [14]

In our study 4 patients (13.3\%) patients had pulmonary affection inform of pulmonary nodules and atelectatic band.

Abdominal and gastrointestinal involvement the most commonly involved extra nodal abdominal site is the spleen, followed by the liver, gastrointestinal tract, pancreas, abdominal wall, genitourinary tract, adrenal, peritoneal cavity, and biliary tract in that order [15]

On our study among $12(40 \%)$ patient had extranodal abdominal non-Hodgkin lymphoma the distribution of lesions was as follow 8 patients (26.7\%) had splenic involvement, 4 patients $(13.3 \%)$ with had liver involvement, 2 patient (6.7\%) had stomach involvement.

Muscloskeletal involvement may involve the bone marrow or cortical bone. Primary lymphoma of the bone accounts for less than $5 \%$ of all bone malignancies [16].

In current study the distribution of extranodal musculoskeletal affection was detected by PET/CT in 10 patients $(62 \%)$, bone marrow in 7 patients $(21.7 \%)$, cortical bone: 3 patients $(9.1 \%)$, and skeletal muscles: 1 patient $(6.25 \%)$.

The degree of FDG uptake can be expressed quantitatively by means of the Standardized Uptake Value (SUV), it represents the activity in the lesion in $\mathrm{Ci} / \mathrm{ml}$ corrected for the weight of the patient and the dose of FDG administered. It is useful to know the tumor SUV before initiation of therapy to assess tumor grade and evaluate treatment response following radiation therapy or chemotherapy.

The SUVmax indicates that the maximum value of the measured value in the $2 \mathrm{~cm}$ lesion is a more accurate estimate of the true SUV than SUVmean. For this reason the use of the maximum SUV value, defined here as SUVmax, is becoming more common. 
In current study, we had 30 patients referred for initial assessment of non-Hodgkin lymphoma, their SUVmax ranged from 3.70-34.0 with mean value of $16.46 \pm 7.53 \mathrm{SD}$, the SUVmax in aggressive type of NHL ranged from 10.5-34.0 with mean value of $19.89 \pm 6.65 \mathrm{SD}$ and that of indolent NHL ranged from 3.70-10.0 with a mean value of 7.10 \pm 2.49 , where aggressive type of NHL is significantly higher $(p \leq 0.01)$ than in indolent type.

Among the 20 patients referred for follow-up assessment in the present study, we found that their baseline SUVmax PET/CT examination ranged from 3.7-34.0 with a mean value of $17.57 \pm 8.54$ $\mathrm{SD}$, with a significant change $(p \leq 0.046)$ in their follow-up examination with SUVmax ranged from $0.0-28.0$ with a mean value of $11.73 \pm 9.25 \mathrm{SD}$.

In our study, among the 30 cases referred for initial staging and according to the Ann Arbor classification of non-Hodgkin's Lymphoma, the cases were staged as follows; CECT detected 6 (20\%) patients in stage I, $9(29.3 \%)$ patients in stage II, $7(23.3 \%)$ patients in stage III and $1(3.3 \%)$ patient in stage IV. The PET/CT detected $4(13.3 \%)$ patients in stage I, 8 (26.7\%) patients in stage II, $13(43.3 \%)$ patients in stage IV and significantly identified $(p \leq 0.19)$. Thus, PET/CT agreed with CECT in 13 cases $(43.4 \%)$ and disagreed with it in $17(56.7 \%)$ cases, where PET/CT upstaged 13 cases and down staged 4 cases.

In a previous study. PET/CT was used in initial staging of 41 cases. PET/CT and conventional imaging methods were concordant in the staging of 30 patients $(73.2 \%)$ and discordant in remaining 11 patients $(26.8 \%)$. PET/CT upstaged 5 patients (12\%) out of the 11 discordant cases and downstaged 6 patients (14.5\%). 2 patients were upstaged from stage I to stage II. 1 patient from stage II to stage III. 2 cases $(4.8 \%)$ were upstaged to stage IV, 1 patient from stage II to stage IV [4].

PET/CT impacts not only the staging, but also the therapy protocol, in lymp + homa staging, $\mathrm{PET} / \mathrm{CT}$ tends to upstage rather than downstage tumors [17]

In our study, among the 20 patients referred for follow-up assessment after treatment according to the size in CECT and FDG activity in PET/CT; CECT showed 4 patients (20\%) in complete regression, 2 patients $(10 \%)$ in partial remission, 13 patients $(65 \%)$ in stable disease and 1 patient $(5 \%)$ in progressive disease while PET/CT showed 7 patients $(35 \%)$ in complete remission, 4 patients $(20 \%)$ in partial remission, $0(0.0 \%)$ patients in stationary disease, $9(45 \%)$ patients in progressive disease.

In a large retrospective study they studied 151 patients with mediastinal lymphoma, 94 cases of NHL (62.2\%). The follow-up program for each patient included 18F-FDG PET every 6 months, results suggested lymphoma relapse in 30 of 151 patients after the completion of therapy.

\section{Conclusion:}

PET/CT combines the advantages of the excellent functional information provided by PET and the superb spatial and contrast resolution of CT, PET/CT imaging plays a vital part in the staging procedure, may upstage or pick up occult lesions such as splenic, bone marrow, osseous, and gastrointestinal involvement which may be missed on conventional CT.

PET/CT proved statistically to be more efficient in follow-up studies after chemotherapy using the Standard Uptake Value (SUV) being more related to the functional activity of the residual tumor cells rather than to the size of the tumor itself.

\section{References}

1- ABDELHAMID T., SAMRA M., RAMADAN H., MEHESSIN M. and MOKHTAR N.: Clinical prognostic factors of diffuse large B cell non-Hodgkin lymphoma. J. Egypt Natl. Canc. Inst., 23 (1): 17-24, 2011.

2- PAES F.M., KALKANIS D.G., SIDERAS P.A. and SERAFINI A.N.: FDG PET/CT of extranodal involvement in Non-Hodgkin lymphoma and Hodgkin disease. Radiographics, 30: 269-91, 2010.

3- JEMAL A., SIEGEL R., WARD E., HAO Y., XU J., MURRAY T., et al.: Cancer statistics. CA Cancer J. Clin., 58: 71-96, 2008.

4- RIAD R., OMAR W., KOTB M., HAFEZ M., SIDHOM I., ZAMZAM M., et al.: Role of PET/CT in malignant pediatric lymphoma. Eur. J. Nucl. Med. Mol. Imaging, 37: 319-29, 2010

5- AGALE S.V., D'COSTA G.F., HASTAK M.S. and SHEDGE R.K.: Primary non-Hodgkin's lymphoma of the salivary gland: A spectrum of lymphoepithelial sialadenitis, low-grade B-cell lymphoma of the mucosa associated lymphoid tissue with transformation to high grade lymphoma. Indian J. Pathol. Microbiol., 53: 364-7, 2010.

6- TEREZAKIS S. and YAHALOM J.: PET-computed tomography for radiation treatment planning of lymphoma and hematologic malignancies. PET Clin., 6: 165-75, 2011.

7- CATALANO O.A., ROSEN B.R., SAHANI D.V., HAHN P.F., GUIMARAES A.R., VANGEL M.G., et al.: Clinical impact of PET/MR imaging in patients with cancer undergoing same-day PET/CT: Initial experience in 134 patients-a hypothesis-generating exploratory study. Radiology, 269: 857-69, 2013. 
8- BUCHBENDER C., HEUSNER T.A., LAUENSTEIN T.C., BOCKISCH A. and ANTOCH G.: Oncologic PET/MRI, part 1: Tumors of the brain, head and neck, chest, abdomen, and pelvis. J. Nucl. Med., 53: 928-38, 2012.

9- TERASAWA T., NIHASHI T., HOTTA T. and NAGAI H.: 18F-FDG PET for post therapy assessment of Hodgkin's disease and aggressive non Hodgkin's lymphoma: A systematic review. J. Nucl. Med., 49: 13-21, 2007.

10- KWEE T.C., KWEE R.M. and NIEVELSTEIN R.A.: Imaging in staging of malignant lymphoma: A systematic review. Blood, 111: 504-16, 2008.

11-ZHANG Q.Y. and FOUCAR K.: Bone marrow involvement by Hodgkin and non-Hodgkin lymphomas. Hematol. Oncol. Clin. North Am., 23 (4): 873-902, 2009.

12- FUEGER B.J., YEOM K., CZERNIN J., SAYRE J.W., PHELPS M.E. and ALLEN-AUERBACH M.S.: Comparison of CT, PET, and PET/CT for staging of patients with indolent non-Hodgkin's lymphoma. Mol. Imaging Biol., 11: 269-74, 2009.
13- NAKAMOTO Y., TATSUMI M., HAMMOUD D., COHADE C., OSMAN M.M. and WAHL R.L.: Normal FDG distribution patterns in the head and neck: PET/CT evaluation. Radiology, 234: 879-85, 2005.

14- WEEKS J.C., YEAP B.Y., CANELLOS G.P. and SHIPP M.A.: Value of follow-up procedures in patients with large-cell lymphoma who achieve a complete remission. J. Clin. Oncol., 9: 1196-203, 2009.

15- DODD G.D.: Lymphoma of the hollow abdominal viscera. Radiol. Clin. North Am., 28: 771-83, 2004.

16- EVEN-SAPIR E., LIEVSHITZ G., PERRY C., et al.: Fluorine-18 Fluorodeoxyglucose PET/CT Patterns of Extranodal Involvement in Patients with Non-Hodgkin Lymphoma and Hodgkin's Disease. Radiol. Clin. N. Am., 45: 697-709, 2007.

17- RANANI P., SHASHA Y., PERRY C., METSER U., NAPARSTEK E., APTER S., et al.: Is CT scan still necessary for staging in Hodgkin and non-Hodgkin lymphoma patients in the PET/CT era? Ann. Oncol., 17: 117$22,2006$.

\title{
دور المسح البوزيترونى بالآشعة المقطعية

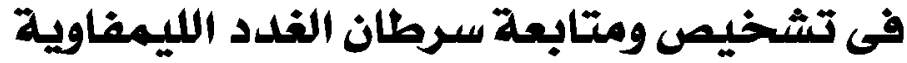 من نوع الغير هودجيكن وتقيييم إمتداداه خارج الغدد الليمفاوية اليمادية
}

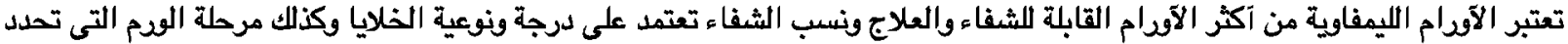

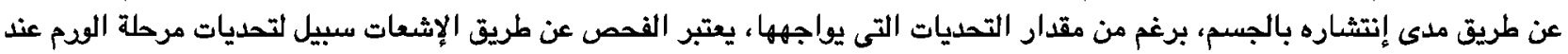
إكتثافه لآول مرة وكذالك مدى إستجابته العلاجه.

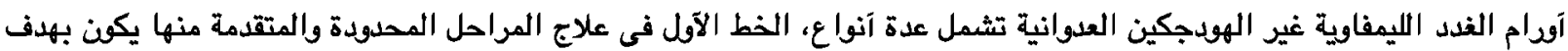

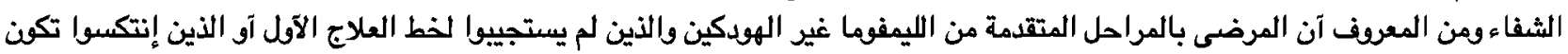

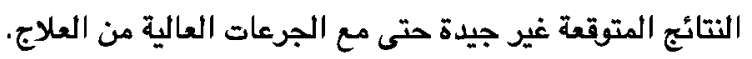

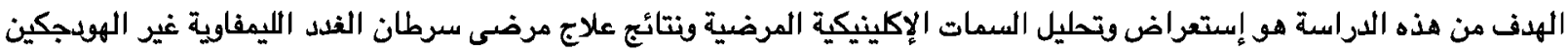

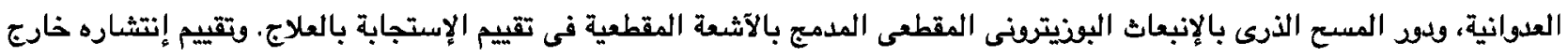
العقد الليمفاوية.
\end{abstract}

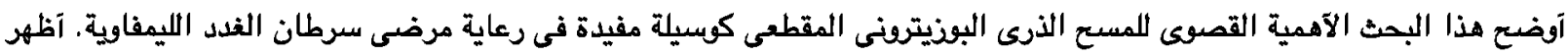
المسيح الذرى البوزيترونى المقطعى قيمة كبيرة فى تحديد مدى الإستجابة للعلاج، والكشف المبكر عن إرتجاع المرض، كما آنه دقيق فى وصف الكتلة المتبقية من الومث.

توصى هذه الدراسة آن يكون المسح الذرى البوزيترونى المقطعى آقل وسيلة مستخدمة فى كل آغراض تحديد مرحلة المرض، مدىى الإستجابة العلاج الكثف المبكر عن إرتجاع المرض، والمتابعة فى هذه المرحلة العمرية. 